\title{
Beauty, A Social Construct: The Curious Case of Cosmetic Surgeries
}

\author{
Tanushri Roy ${ }^{1}$ and Vandana Roy ${ }^{2 *}$ \\ ${ }^{1}$ University of Delhi, India \\ ${ }^{2}$ Department of Pharmacology, University of Delhi, India
}

Submission: July 19, 2018; Published: July 24, 2018

*Corresponding author: Vandana Roy, Department of Pharmacology, Maulana Azad Medical College, University of Delhi, India; Tel: +919968604283; Email: roy.vandana@gmail.com

Abstract

In this article we deconstruct the social norm of beauty and cosmetic beauty treatment, an issue that is seldom discussed in medical circles and is often lost to popular rhetoric. In doing so, we also reflect on the institutionalized system of social conditioning.

\section{A Historical Perspective}

Cosmetic surgery, as with reconstructive surgery, has its roots in plastic surgery (emerging from the Greek word 'plastikos', meaning to mold or form). The practice of surgically enhancing or restoring parts of the body goes back more than 4000 years. The oldest accounts of rudimentary surgical procedures is found in Egypt in the third millennia BCE. Ancient Indian texts of 500 BCE outline procedures for amputation and reconstruction. The rise of the Greek city-states and spread of the Roman Empire is also believed to have led to increasingly sophisticated surgical practices. Throughout the early Middle Ages as well, the practice of facial reconstruction continued. The fifth century witnessed a rise of barbarian tribes and Christianity and the fall of Rome. This prevented further developments in surgical techniques. However, medicine benefited from scientific advancement during the Renaissance, resulting in a higher success rate for surgeries. Reconstructive surgery experienced another period of decline during the 17 th century but was soon revived in the 18th century. Nineteenth century provided impetus to medical progress and a wider variety of complex procedures. This included the first recorded instances of aesthetic nose reconstruction and breast augmentation. Advancements continued in the $20^{\text {th }}$ century and poured into present developments of the $21^{\text {st }}$ century.

\section{Desires and Demands in Contemporary Times}

In recent years, the volume of individuals seeking cosmetic procedures has increased tremendously. In 2015, 21 million surgical and nonsurgical cosmetic procedures were performed worldwide. In the United Kingdom specifically, there has been a $300 \%$ rise in cosmetic procedures since 2002. The year 2016 witnessed a surge in the number of such treatments with the
United States crossing four million operations. Presently, the top five countries in which the most surgical and nonsurgical procedures are performed are the United States, Brazil, South Korea, India, and Mexico. Such demand can be viewed from different perspectives. At one end it is a product of scientific progress, growing awareness, economic capacities and easier access and on the other, something on the lines of a self-inflicted pathology. This article dwells on the latter and attempts to address a deep-rooted problem of the social mind.

\section{Lessons from History}

History is witness to a number of unhealthy fashion trends, many of which today appear extremely irrational and even cruel. Interestingly, the common thread connecting all of them is the reinforcement of social norms and stereotypes. Forms of socialization which lie at the intersection of race, class and gender-based prejudices. To elaborate, hobble skirts and chopines restricted women's movement and increased their dependence on others. Corsets deformed body structures, damaged organs and led to breathing problems. The Chinese practice of binding women's feet to limit physical labor was regarded as a sign of wealthiness. Dyed crinolines and 17th century hairstyles made people vulnerable to poisoning and fire related injuries. Usage of makeup made of lead and arsenic, eating chalk and 'blot letting', reflected a blatantly racist obsession with white and pale skin. Lower classes faked gingivitis to ape tooth decays of the more privileged who had access to sugar. Furthermore, other practices like tooth lacquering, radium hair colors, mercury ridden hats, usage of belladonna to dilate pupils and even men wearing stiff high collars, all furthered societal expectations and notions of 
class superiority. Till the 1920's, there was rampant usage of side lacers to compress women's curves. Even today many ethnic tribes continue with practices which inflict bodily deformations. In the urban context as well, trends like high heels, skinny jeans and using excessive makeup dominate the fashion discourse. Cosmetic procedures are the latest addition to the kitty.

\section{The Social Dilemma}

What is it that leads the 'intelligent human' of today to succumb to archaic and regressive notions of beauty? What motivates them to risk aspects of their lives to cater to selflimiting rules of 'acceptance'? The surprising part is that this anomaly is often placed in the illusory realm of 'informed consent'. In common parlance, 'to consent' implies voluntary agreement to another's proposal. The word 'voluntary' implies 'doing, giving, or acting of one's own free will.' However, when the entire socio-cultural set up and individual attitudes validate certain behaviors, there is very less space left for an alternate narrative. Let alone free will.

Pierre Bourdieu once argued that nearly all aspects of taste reflect social class. Since time immemorial, societal standards of beauty have provided stepping stones to social ascent and class mobility. Better 'looking' individuals are considered to be healthier, skillfully intellectual and economically accomplished in their lives. Such an understanding stems from well entrenched stereotypes in complete disregard of individual merit and fundamental freedoms. An inferiority complex coupled with external pressures and self imposed demands, subconsciously coerce individuals into a vicious cycle of desire or rejection. Active and aggressive media has played a key role in forming societal perceptions of what is attractive and desirable. In addition, lifestyle changes reflect an image obsessed culture, reeking of deep-rooted insecurities. At the root of a submissive and conformist attitude lies a subconscious mind lacking selfesteem and self-worth. People continue to look for remedies in the wrong places. The only difference is that corsets and blot letting have given way to surgeries and cosmetic products. The biggest question is, how have ideas otherwise seen as deviant, problematic and inadequate retained control over minds of millions of individuals?

\section{A Gendered Culture}

'Beauty' is understood as a process of ongoing work and maintenance, its 'need' unfairly tilted towards the fairer sex. History has demonstrated the impact of dangerous beautification practices on women. Contemporary ideals aren't far from reaching similar outcomes. Today, there is a powerful drive to conform to the pornographic ideal of what women should look like. There has been a growth in the number of adolescents who take to cosmetic surgeries to become more 'perfect'. In many countries, the growth of the "mommy job" has provoked medical and cultural controversies. Presumably there is an underlying dissatisfaction which surgery does not solve. Furthermore, where does the disability dimension fit in here? What happens to the 'abnormal' when the new 'normal' itself is skewed? For those with dwarfism and related disorders, new norms become even more burdensome.

The massive pressure to live up to some ideal standard of beauty, particularly for women, reeks of patriarchal remnants of a male dominated society. This kind of conformity further nurtures objectification and sexualization, reducing women to the level of 'chattel' to feed the male gaze. There is a also a power struggle at play where biased standards help maintain the unequal status quo. Today, there is idolization of celebrities, beauty pageants and advertisements by cosmetic companies over sane medical advice. They set parameters of size, color and texture to be followed by the world at large. Moreover, people who deviate from such norms are made to feel stigmatized or ostracized from social spheres. The existence of male-supremacist, ageist, hetero sexist, racist, class-biased and to some extent, eugenicist standards reflect a failure of society as a whole. It is thus high time that we revisit and deconstruct skewed standards of beauty.

\section{Mind Over Matter: Psychological Dimensions}

Culturally imposed ideals create immense pressure of conformity. Consequently, they have been successful in engendering insecurities via their influence on perception of self and body image. Such perceptions often become distorted and discordant with reality, leading to serious psychological disorders. One such disorder is the body dysmorphic disorder (BDD). This is a psychiatric disorder characterized by preoccupation with an imagined defect in physical appearance or a distorted perception of one's body image. It also has aspects of obsessive-compulsiveness including repetitive behaviors and referential thinking. Such preoccupation with self-image may lead to clinically significant distress or impairment in social and occupational functioning. With reference to cosmetic surgeries, patients with BDD often possess unrealistic expectations about the aesthetic outcomes of these surgeries and expect them to be a solution to their low self-confidence. Many medical practitioners who perform cosmetic surgery believe themselves to be contributing towards construction of individual identity as well. The notion that beauty treatments can act in much the same way as psychoanalysis has led countries like Brazil to open its gate of cosmetic procedures to lower income groups. This happens while the country continues its battles with diseases like tuberculosis and dengue. The philosophy behind such 'philanthropy' is that 'beauty is a right' and thus should be accessible to all social groups. While on one hand we may applaud such efforts of creating a more 'egalitarian' social order, on the other hand it is hard to overlook the self-evident undercurrents of social prejudice and capitalistic propaganda.

\section{Medicalization of Beauty}

Traditional notions of beauty embody a kind of hierarchy and repression which alienate individual agency and renders them as 
powerless victims. Such is the societal pressure which normalizes cosmetic procedures and subverts serious health effects. These include adverse effects due to cosmetic fillers like skin necrosis, ecchymosis, granuloma formation, irreversible blindness, anaphylaxis among others. Other dangers like heightened susceptibility to cancer and increased suicide rates. However, patients are often unaware of the risks which are hidden behind a veil of expectations and reassurances. Furthermore, quackery and inadequate standards such as lack of infection control also compound the problems of this under regulated field.

\section{Role of Stakeholders}

At the heart of any successful social transformation lies the power of united will and collective action. Thus, the consolidated and sustained effort by all stakeholders is the key to realizing an ecosystem conducive to tackle negative social norms. At the outset, government regulation is needed with respect to cosmetic procedures and the cosmetics industry. These regulations should encompass all private and public avenues and should also work against misleading advertising. Spreading awareness is the key to a better informed society. The state should fund and run specialized awareness sessions pertaining to psychological problems and aid mechanisms, gender sensitization as well as those aiming at spiritual and introspective personal development of individuals. NGO's, medical professionals, academicians and members of the civil society, must come together to eradicate forms of social discrimination which undermine social institutions and individual agency around the world. This would help facilitate discussion, data collection, coalition building, and action that may eventually lead to behavioral changes.

Aesthetic surgery today seems to be passing through an ethical dilemma and an identity crisis. And rightly so for it strives to profit from an ideology that serves only vanity, bereft of real values. Nevertheless, there are exceptional cases where medical-aesthetic inputs have been vital in restoring morale by subverting stigmatization.

\section{The Way Ahead}

Beauty is unfair. The 'attractive' enjoy powers gained without merit. The perfectionist in humans seeks outward validation of external beauty over inner virtues. Scientific progress and an increase in human expertise to manipulate natural phenomena has paved the way for these desires to become a reality. There is no denying that advances in plastic and reconstructive surgery have revolutionized the treatment of patients suffering from disfiguring congenital abnormalities, burns and skin cancers. However, the increased demand for aesthetic surgery falls short of a collective psychopathology obsessed with appearance. This article expresses trepidation about such forms of social consciousness that first generates dissatisfaction and anxiety and then provides surgery as the solution to a cultural problem.

We have to work towards a social order which embraces people as they are and facilitates free choice, individual liberty and informed decision making. This is particularly pertinent when these decisions work towards framing cultural perceptions and expectations for millions around the world. We should open our hearts to diversification of beauty and aesthetic. Let our entertainment, fashion, capital and media revolve around heterogeneity of ideologies and cultures. In the words of Eleanor Roosevelt, "No one can make you feel inferior without your consent". So, let us all come together and create a better society. A society, where principles of justice, equity, good conscience and humanity override primitive and archaic ideologies of naive men. A society where individual will be truly free and, discourse a product of informed thought.

\section{Your next submission with Juniper Publishers will reach you the below assets}

- Quality Editorial service

- Swift Peer Review

- Reprints availability

- E-prints Service

- Manuscript Podcast for convenient understanding

- Global attainment for your research

- Manuscript accessibility in different formats ( Pdf, E-pub, Full Text, Audio)

- Unceasing customer service

Track the below URL for one-step submission https://juniperpublishers.com/online-submission.php 